\title{
SCIENTIFIC RESEARCH WITHIN THE FRAMEWORK OF UNIVERSITY MANAGEMENT
}

\author{
Dr. Jorge Daher Nader ${ }^{* 1} \bowtie$, Dr. Amelia Patricia Panunzio ${ }^{1}$, Dr. Marlene Hernández \\ Navarro ${ }^{2}$ \\ ${ }^{* 1}$ Professor at the University of Guayaquil, Ecuador \\ 2 University of Zulia, Venezuela
}

DOI: https://doi.org/10.29121/granthaalayah.v8.i10.2020.1680

Article Type: Research Article

Article Citation: Dr. Jorge Daher Nader, Dr. Amelia Patricia Panunzio, and Dr. Marlene Hernández Navarro. (2020). SCIENTIFIC RESEARCH WITHIN THE FRAMEWORK OF UNIVERSITY MANAGEMENT. International Journal of Research GRANTHAALAYAH, 8(10), 47-57. https://doi.org/10.29121/granthaa layah.v8.i10.2020.1680

Received Date: 20 September 2020

Accepted Date: 23 October 2020

Keywords:

Scientific

Research

University

Management

\begin{abstract}
Research management is conceptualized as the institutional activity oriented to the search, study, knowledge of reality, systematization of this knowledge and its transfer to satisfy needs and contribute to solving the problems of society. The results obtained in this article about scientific research, seem to be common to the scope of this research; What is clear is that the low motivation of teachers for research constitutes a common denominator in the universities of Ecuador, which, in the opinion of the author, can be increased if the management of the research process favors the institutional, administrative, curricular conditions that articulate the practice of teaching with research practice.
\end{abstract}

\section{INTRODUCTION}

A quantitative study with a transectional design, entitled "The perceptions of teachers regarding research and innovation in their professional contexts" (Díaz, Solar, Soto and Conejeros, 2015) aimed to analyze training processes associated with the ability to develop research, educational innovation, leadership spaces and internal communication, and school-family linkage in educational establishments in Chile. The sample consisted of 108 preschool, elementary and middle school teachers, belonging to public, semi-public and private establishments in the Biobio Region in Chile. To collect the information, the survey technique was used, in order to obtain quantitative measurements on a large number of objective and subjective characteristics of the study sample. To measure the teachers' perception, the questions were formulated through a Likert Scale, which considers the intensity of the expression of attitude.

To perform the information analysis, descriptive statistics were applied. This process included analysis of frequency distribution, measures of central tendency and measures of dispersion. The results show that the teachers

(C) 2020 The Author(s). This is an open access article distributed under the terms of the Creative Commons Attribution License, which permits unrestricted use, distribution, and reproduction in any medium, provided the original author and source are credited. 
surveyed do not consider that research is part of their teaching practices. Despite the fact that a large part of teachers acknowledge making innovations, they are perceived as an isolated instance, detached from directive leadership. The findings also indicate that teachers exercise leadership at the pedagogical and managerial level. Internal communication is valued positively by teachers, however, the link between school and family is weak. At the level of continuous training, teachers consider that the instances of improvement do not promote personal development.

This research allows the author to make a critical analysis about the perception of teachers about scientific production, which constitutes objective three of this project, when analyzing these results it is necessary to reflect and systematize the factors that could influence this indicator from the perspective of the teachers

The bases that will serve as theoretical support and will allow to form the platform on which the analysis of the results will be built and therefore the fulfillment of the objectives, arise from the exhaustive review of a wide and varied bibliography. They are related to: the theoretical model as a scientific result, quality in higher education, university research management, knowledge management for research, scientific production at the university and user satisfaction in terms of scientific production at the university. Each of them are presented below:

The theoretical model as a scientific result.-When analyzing the word "model" it can be seen with two fundamental opposing senses in natural language. In one of them, "model" would refer to what has been represented, painted or photographed. In the second sense, one would speak of the opposite extreme of the relationship: representation, painting, photography (Rivadulla2004, cited by Arboleda 2014). There are different classifications of the model (Bolonio, 2004; Echevarría, 1995). According to Echeverría (1989) he distinguishes "five types of different models":

1) Logic models. They constitute a series of semantic interpretations of an axiomatic system. In these interpretations, what is specified by the theory is fulfilled, so that the axioms are true. There is a structural isomorphism between the theory and the model.

2) Mathematical models. In this case, the structural isomorphism occurs between the empirical laws and a set of mathematical formulas that share the same form. They are mathematical representations of a physical theory.

3) Analog models. In this type of representations the mechanical Kelvin models would enter, a planetary system to scale, or a three-dimensional graphic representation of an object or a real system. It is assumed that isomorphism continues to exist.

4) Imaginary models. Here the models specify a series of conditions that are not met in reality. Representation idealizes reality and studies it as if it were so, even if it is not. Examples would be Maxwell's magnetic field model or Poincaré's Universe model taking into account Lobachevski's geometry.

5) 5). Theoretical models: are those where the representation is achieved from a series of assumptions about the real structure of a system. Here the Bohr atomic model is cited, or the billiard ball model used in kinetic theory of gases.

A theoretical model is a synthesis of a phenomenon, understood as a rational reconstruction of the available information, as an explanatory principle of observable reality, as the shortest and most accurate expression that describes what is known to date of a certain phenomenon, constructed from a series of accepted premises, and whose utility lies in the prediction of new aspects and measurements of reality.

A theoretical model does not become true or false, but rather more or less acceptable, more or less useful, according to its ability to deductively justify a series of statements considered true (Echeverría, 1989; Vélez, 2006).

In research language the representations are called "Theories" or "Theoretical Models". Theories when it has a wide scope (includes a large number of phenomena) and its high level of formalization and Theoretical Model when its scope is smaller or limited to some portions of the empirical world. Both theories and theoretical models are systems of concepts. In other words, they are sets of related concepts. The phenomena can be represented by related concepts. There are various models, which after adaptation can be used in the educational field. Management models are widely referred to in this area, and within them total quality models, thus the Deming model created in 1951, the Malcolm Baldrige model in 1987 and the European Quality Management Model, EFQM created in 1992, are the most widely used. world level.

López (2014) affirms that a management model "allows establishing an approach as well as an objective, rigorous and structured frame of reference for the diagnosis of the organization, as well as to determine the lines of continuous improvement towards which the efforts of this". 
In the author's opinion (Daher,2019), the creation of a model to strengthen scientific production in the Faculty of Medical Sciences of the University of Guayaquil offers the following benefits: the indicators are defined to evaluate scientific production, it provides a more exact understanding of the research reality in the university and makes it possible to measure scientific activity with the same criteria and provide solutions in the short, medium and long term

Quality in Higher Education- The term quality is present in all actions and scenarios of daily life. Quality is related to effectiveness, efficiency, a state of satisfaction, conformity and service. Quality is a complex concept to define and has different meanings for all students of the subject. For example, according to Díaz (2008), quality consists of satisfying the standards established for inputs, processes and, mainly, results.

For Lago, López, Municio, Ospina and Vergara (2013), quality is the result of comparing expectations with the perception of the service received. Therefore, it can be affirmed that an important indicator in the measurement of quality is the satisfaction of the people who receive a certain service.

According to the International Standard Organization for Standardization (ISO), the term of quality is: - "The set of characteristics of an entity (product, service, process, activity, organization, etc.) that confers it the ability to satisfy the explicit needs and implicit..."(ISO 8402/1994).

When talking about quality in higher education, it is necessary to mention the UNESCO Regional Conference (UNESCO, 1998), in which it was proposed that quality could be defined as the transformation of the being and the work of higher education to its duty to be. In this Conference it was defined that the quality of higher education appears linked to a current problem of extreme complexity, which includes:

- The expansion that higher education has experienced in Latin America.

- The structural deficiencies of the educational systems, given among other things by the scarce interrelation and coherence between their different levels.

- The alarming decline in budgets to meet the growing needs

- The need to assume curricular innovation processes in accordance with social needs

- The continuous improvement of the teaching-learning process from all its components.

- The vertiginous advance of knowledge and access to information

To achieve quality in higher education, it is necessary to experience great changes in the institutions that lead to transformations in their academic, administrative and financial processes. At the present time worldwide great changes are happening in university systems. Experts in the field of higher education have already affirmed that the 21st century will be the period of greatest growth in higher education in the history of education, with important changes in the system, so that universities will be forced to make adjustments. in order to fit in with the management systems of the financial public sector (Palomares and García, 2010; Palomares, García and Castro, 2008); Rodríguez, 2005).

"One of the most important references for research on the quality of Higher Education is the Bologna treaty, constituted in 1999, this treaty revolutionized higher education in Europe with important effects in Latin America and the Caribbean. The navigation route proposed by Bologna sought to create a competitive European Higher Education Area, attractive to both students and teachers, and attractive to other countries. Some of the main changes that were sought in this treaty were curricular adaptations and technological adaptations, the adoption of a system of university degrees easily comparable throughout Europe, which opened up the mobility of students and research professors through European universities, at the same time that continuous learning and the quality of Education were promoted "(Ceballos, Cantarero and Pascual, 2004).

The Bologna treaty has had a great impact on the quality of Higher Education in Europe, as well as in Latin America and the Caribbean. The governments and universities of Latin America have undertaken transformations in education in order to standardize the curricular designs of the different professional careers as well as the evaluation system that accredits them so that professionals can exercise mobility as required by university quality (Bulgarín, 2008).

Institutional and program evaluations have been implemented in Latin America for some years, with the aim of having mechanisms for ensuring the quality of education. This process has been influenced by conjuncture elements Ecuadorian higher education must be relevant and of quality so that it contributes to identifying and solving society's problems, that is, it must be responsible and committed to the creation, development and transmission of knowledge.

"So quality plays a supremely important role, which implies that all actors linked to higher education act responsibly in the generation and consolidation of a self-regulatory attitude, seeking that it does not become an 
Scientific Research Within the Framework of University Management

individual project, but rather more than be a task for everyone, be a permanent, participatory process and become a common practice"(National Council for the Evaluation and Accreditation of Higher Education of Ecuador CONEA, 2003)

At the National Conference "Higher Education in Ecuador. Investigations for a New Agenda for Necessary Changes" held in 2017, the achievements and criticisms of the Ecuadorian higher education system were analyzed and it was proposed that the main purpose is to give public guarantee of quality, through the installation of accreditation mechanisms and certification of careers.

Article 93 of the Higher Education Law contemplates that the principle of quality consists of the constant and systematic search for excellence, relevance and optimal production, transmission of knowledge and development of thought. Later, in Article 94, in relation to the evaluation of quality, it provides that the evaluation of quality is the process to determine the conditions of the institution, career or academic program, through the systematic collection of quantitative and qualitative data that allow issuing a judgment or diagnosis, analyzing its components, functions, processes, so that its results serve to reform and improve the institution's study or career program (LOES, 2010).

University Research Management- Research is considered a function aimed at obtaining new knowledge and its application to solve problems or questions of a scientific nature. Management is defined as the set of actions aimed at the development and fulfillment of an activity. Thus, research management is conceptualized as the institutional activity oriented to the search, study, knowledge of reality, systematization of this knowledge and its transfer to satisfy needs and contribute to solving the problems of society.

University research management must have a continuous improvement approach based on methodologies that, although different, have as a common denominator: the identification, characterization, evaluation and improvement of the process. (Villa, Pons 2013)

Mantilla, 2007 affirms that "Research in this sense revolves around the conceptions of the administration disciplines from the point of view of planning, management and evaluation with reference to quality, which better interpret actions in the context of the research, whether with reference to subjects, groups (teams), centers or bodies and research systems. Their organizational coordinates, the way in which the incidence of the disciplines of knowledge and the objectives of research projects and plans act and the object on which they develop their action in a different context if it is a university or private company."

In the author's opinion (Daher,2019), in order to achieve quality management, the research development policies at the University must be adjusted to the national policies that aim to strengthen scientific and technological research, although the university can formulate its own proposals. Higher education institutions must develop research programs, in which the priority lines to be worked on are identified through the centers of excellence, and / or Research Departments of their academic units.

These lines must be in relation to state policies, with the main problems of society identified, as well as with the Vision and Mission of the University and the faculties, and therefore contribute to the institutional development and the broad social project of contributing to the development of the country.

The author affirms that it is currently a need to carry out quality research management that fosters processes of scientific collaboration between universities, research centers, the national government, local governments and the productive sector, to unify criteria and efforts that allow the development of basic research, applied and technological.

The construction of strategic alliances to promote research in a more planned and systematic way is a necessity of higher education. Strategic alliances will promote the opening to new horizons of knowledge, propit

But how to evaluate university management for research? The management of the university institution has an impact not easily identifiable on the dimensions that are conventionally used for the evaluation of research activities. Evaluating management activity for scientific activity is a dynamic and complex process. There are indicators established in each institution framed in the Strategic Plan for Institutional Development that range from planning and execution to control and evaluation. A planned and systematic evaluation will allow correcting in time the imperfections present in the research process and therefore strategies that facilitate the management of research in universities can be drawn up.

Knowledge management for research is a new form of economic growth focused on innovation and the creation of a "knowledge society", in which the development and exchange of knowledge between people is its most important engine of progress (Zamora, 2003). 
Similarly, Del Moral, Pazos, Rodríguez, Rodríguez and Suárez (2007) state that it consists of making the tacit knowledge of each of the members belonging to it available to the institution, in an orderly, practical and effective manner, in order to achieve a better operation and productivity.

"Consolidating knowledge management according to social demands implies specifying guiding criteria for managerial action in order to shape favorable responses to changes in both the external and internal contexts of university institutions. Indeed, the knowledge base of a social organization must consist of the individual and collective intellectual assets used in them to carry out their activities; as well as the inclusion of data and information on which individual knowledge and that of the organization have been built. This implies the search for relevant procedures to generate innovative alternatives that lead to the effective achievement of the objectives set at the administrative and pedagogical levels. " (Oñate and Urdaneta, 2016)

Rodríguez (2006) addresses the issue of knowledge management based on the formation of academic networks as determinants of quality, and studies that analyze the debates on education laws in Latin America, mainly referring to teacher training and research.

"Currently, in higher education organizations, the opening towards a paradigm that guides educational management towards flexible and human structures also called light must prevail. It will therefore be necessary to promote changes in the base of explicit and tacit knowledge, linked to the creation of collective reference frameworks and the development of the organization's skills to act and solve problems, which could have an impact on efficient organizational learning. and effective. Coupled with an enormous capacity for abstraction, imagination, human sensitivity and, of course, creativity. " (Oñate and Urdaneta, 2016)

On the other hand, Sánchez (2005), when approaching research management from the reality of Latin American universities, reveals deficiencies in research as a process and of course in knowledge management, which he describes by highlighting the aspects referred to the traditional figure of the university as an academic-institutional space where teaching, research and links with society are articulated.

In the author's opinion, knowledge management for the training of researchers in universities requires the commitment of all the subjects involved in the process of generating knowledge, assuming the research for and teaching with which it must function in full relationship.

In this regard, Sánchez (2005) states: "This area of scientific endeavor is promising for the training of the professor-researcher from the moment in which the link between research and teaching is considered as a strategic way to raise the quality of higher education. This research context, although closely related to educational research itself, retains its own characteristic features that little by little, and thanks to concrete experiences, are delimited "

In accordance with the aforementioned, it can be said that it is proper to the university to investigate and, above all, guide the investigative process. Therefore, reflective criticism and evaluation of research management must be a systematic and permanent practice in the university environment. It is, in effect, the systematic and intentional mediation of a practical knowledge whose challenges come from several directions: (a) from scientific research as At the Autonomous University, aware of the importance of collecting the scientific production of its researchers, a series of platforms have been developed that collect all the scientific activity of researchers (Scientific Production Portal) and that store the full texts of the publications in those that this production is reflected, in open access, through its institutional repository Biblos-e Archivo.

The Law of Higher Education of Ecuador, LOES, highlights as one of the purposes of higher education scientific production and technological transfers and innovations as a contribution to the development of universal thought. Higher Education Institutions must also allocate resources from their own budgets for the publication of research in indexed journals of their researchers.

Publications are the key component of all scientific activity (Peralta, M Solis, Peralta, L, 2010), and research is one of the fundamental pillars of higher education today, along with teaching and outreach. Then, how scientific production becomes a key element within the quality of Higher Education (Álvarez and Juncosa, 2014)

It is important that those who have the responsibility of directing the scientific activity in the universities, are trained people, who have a scientific degree, who stand out for their constant work of searching for solutions through research and who actively participate in all groups and management levels where the methodological work is developed, which is governed by the objectives set out in the professional model, it is also necessary that the study plans provide spaces for research and establish as cross-curricular axes the subject of research in the training of professionals. It is necessary to insist on the leading role of the university professor in the research process from the subject he teaches, as a facilitator and as a role model for his students. The above indicates the need to think about the research from the teaching performance. (Mur, Casanova, Iglesias and Cortés, 2014).

International Journal of Research -GRANTHAALAYAH 
"Thus, the scientific production (PC) of an institution can be measured based on the number of publications in scientific journals, since it allows evaluating the scope of its contributions to the development of new knowledge. This evaluation can be carried out by analyzing the articles published in indexed journals in databases such as: EMBASE, OVID, HINARI, COCHRANE, LILACS, MEDLINE / Pubmed, SCIELO or SCOPUS.

The low scientific production that universities have, especially medical schools, and especially in medical education (Doja, Horsley, Sampson, 2014) is a current problem in Latin America, so much so that there have been few reports of scientific production of every country in this area.

But how to achieve an increase in scientific production in medical schools? The author affirms that it is a complex but not impossible process, it requires a management of organized processes from teacher training, to achieve the empowerment of research teachers, to the imbrication of students in said processes. In this sense, undergraduate research offers knowledge and tools that raise the student's resolution capacity during their schooling and in their future professional practice. This approach allows us to analyze the research from an integrative perspective, which establishes a scientific culture in terms of creating social security and stimulation for young people who dedicate themselves to research, promoting knowledge networks (Reyes, Aular, Palencia, Muñoz, 2010).

Evaluation indicators of scientific production (bibliometric studies)- The need to measure scientific production has given rise to a new discipline, bibliometrics. The abundant scientific information generated in recent years associated with new forms of communication has led the research community to propose its measurement. Mathematical methods and statistical analyzes that make it possible to obtain reliable indicators associated with quality are used in bibliometric studies.

For Krohling Kunsch (2003), identifying, verifying, analyzing and evaluating the scientific production of an area of knowledge is not an easy task. One of the reasons is related to the difficulty of access to everything that is generated and the lack of a culture that prioritizes research documentation and reference works.

"At present, bibliometric or scientific production indicators are accepted as a valid indicator of research results, along with other indicators such as patents or new products in the most technological areas. As an example of the degree of acceptance that they have reached, we can mention their inclusion in the reports on the situation of science and technology that are issued periodically in the most developed countries, where they complement the information provided by the more traditional input indicators (resources human resources, R\&D expenses). This is the case of the "Science and Enginee ring Indicators" of the USA, the "Science \& Technologie Indicateurs" published by the French Observatoire des Sciences et des Techniques (OST), or the "European Reporton Science \& Technology Indicators" edited by the European Union" (Bordons and Zulueta, 1999,)

In this way, it is possible to obtain information on the number of documents published by an institution or a country, research groups or individuals with the highest scientific productivity.

It has been recognized that high-quality scientific production measured through publications is a source of high impact in the construction of the so-called world rankings of University institutions. There are currently two world rankings, the one prepared by the Scimago group of Spain and the Shanghai Ranking, which, although they use different methodologies, the result they ultimately seek is the same, to be able to classify the Universities according to their quality. (Buelal, Bermúdez, Sierra and Quevedo, 2008)

Bibliometric studies provide quantitative information on articles published at the country, province, city and institutional level, and even at the individual level; These data allow a comparative analysis of scientific productivity (Gauthier, 1998; Devos, 2011)

The function of indicators of scientific activity cannot be limited to accumulating juxtaposed statistical data. They must be integrated to obtain increasingly solid explanations related to science, in general, and in its specific aspects (López and Terrada, 1992).

From the bibliometric indicators, a series of qualities can be specified that, according to Rosa Sancho (1990); Ordorika (2015) are:

- Growth of any field of science, according to the chronological variation of the number of works published in it.

- Aging of scientific fields according to the "half-life" of the references of their publications.

- Chronological evolution of scientific productivity according to the year of publication of the documents.

- Productivity of authors and institutions, measured by the number of their works.

- Collaboration between scientists and institutions, measured by the number of authors per work or research centers that collaborate. 
- Impact or visibility of the publications within the international scientific community, measured by the number of citations they receive from subsequent works.

- Analysis and evaluation of the diffusing sources of the works by means of indicators of the impact of the sources.

- Dispersion of scientific publications among the various sources.

When analyzing the perception of users regarding the research, it should be taken into account from the sociodemographic data, (sex, age, years of professional practice, academic training, professional category, workplace, specialty and attendance at conferences) to elements as important as: motivation and satisfaction with professional development, research skills, research needs and possibilities, team research, documentation, attending congresses, collaborations, designing projects, planning and executing projects, analyzing data, contributing new knowledge , know English, scientific writing, obtain financing, among others.

\section{THIS INVESTIGATION IS SUPPORTED BY THE FOLLOWING LEGAL FRAMEWORK}

- United Nations Educational, Scientific and Cultural Organization (Unesco) (2000, p. 37) declares as a fundamental guideline to respond to current social demands in the countries of Latin America and the Caribbean, the need to " (...) Produce a profound transformation in traditional educational management, which allows the administration of knowledge to be effectively articulated with economic, social, political and cultural demands, breaking the isolation of educational actions (...) ".

- United Nations 2030 Agenda: among the 17 Sustainable Development Goals (SDGs) approved in 2015, SDG 4 is the one that refers to education. Higher education is mentioned in target 4.3 of SDG 4: "By 2030, ensure equal access for all men and women to quality technical, vocational and higher education, including university education".

- Constitution of the Republic of Ecuador: Art. 25: in Section IV Culture and Science It states "People have the right to enjoy the benefits and applications of scientific progress."

- Art. 350: "The higher education system aims at academic and professional training with a scientific and humanistic vision; scientific and technological research; innovation, promotion, development and dissemination of knowledge and cultures; the construction of solutions for the country's problems, in relation to the objectives of the development regime. "

- Art. 385: "The national system of science, technology, innovation and ancestral knowledge, within the framework of respect for the environment, nature, life, cultures and sovereignty, will have as its purpose:... /... 1. Generate, adapt and disseminate scientific and technological knowledge. ... /... 2. Recover, strengthen and 2 enhance ancestral knowledge. ... /... 3. Develop technologies and innovations that boost national production, increase efficiency and productivity, improve quality of life and contribute to the realization of good living. ";

- Organic Law of Higher Education: Chapter I: That the search for truth, the affirmation of identity, cultural development, the domain of scientific and technological knowledge are aims of higher education, which are expressed through research, teaching and the link with the collectivity and constitute priorities for the development of the country. The institutions of the National System of Ecuadorian Higher Education have as their mission the search for the truth, the development of universal and ancestral Ecuadorian cultures, science and technology, through teaching, research and links with the community.

- Article 3, literal b: The institutions of the Ecuadorian National Higher Education System, at their different levels, have the following objectives and fundamental strategies: Prepare professionals and leaders with critical thinking and social awareness, so that they effectively contribute to the improvement of production intellectual property and goods and services, in accordance with the present and future needs of society and the planning of the State, favoring diversity in the academic offer to promote a timely insertion of professionals in the occupational market.

- National Plan A lifetime 2017-2021.-Objective 5. (Policies) Promote research, training, training, development and technology transfer, innovation and entrepreneurship, in conjunction with social needs, to promote change in the productive matrix.

- Statute of the University of Guayaquil.- Article 3.- MISSION.- Generate, disseminate and preserve scientific, technological, humanistic and cultural knowledge in a critical, creative way and for social innovation, through 
the functions of training, research and connection with society, strengthening professional and ethically the talent of the nation and the promotion of good living, within the framework of sustainability, justice and peace. AND THE Article. 5.- The University of Guayaquil, within its responsible autonomy, recognizes knowledge and higher education as a social public good.

\section{THEORETICAL OPERATIONAL FRAMEWORK}

\section{Central Variable: MODEL FOR STRENGTHENING SCIENTIFIC PRODUCTION}

\begin{tabular}{|c|c|c|c|}
\hline Conceptual Definition & Operational Definition & Dimensions & Indicators \\
\hline $\begin{array}{l}\text { Scientific production is the form } \\
\text { through which the knowledge } \\
\text { resulting from intellectual work is } \\
\text { expressed through scientific } \\
\text { research in a certain area of } \\
\text { knowledge, whether or not it } \\
\text { belongs to the academic, } \\
\text { published or unpublished field; } \\
\text { that contributes to the } \\
\text { development of science as a social } \\
\text { activity (Salomón and Martínez, } \\
\text { 2007) }\end{array}$ & $\begin{array}{l}\text { It refers to the } \\
\text { dissemination activities of } \\
\text { scientific knowledge and } \\
\text { will be measured through: } \\
\text { number of regional } \\
\text { publications and in high } \\
\text { impact journals and the } \\
\text { number of books or book } \\
\text { chapters, among others } \\
\text { (Dáher, 2018) }\end{array}$ & $\begin{array}{c}\text { University } \\
\text { management in } \\
\text { research (Oñate, } \\
\text { 2016; } \\
\text { Villa,2013) }\end{array}$ & 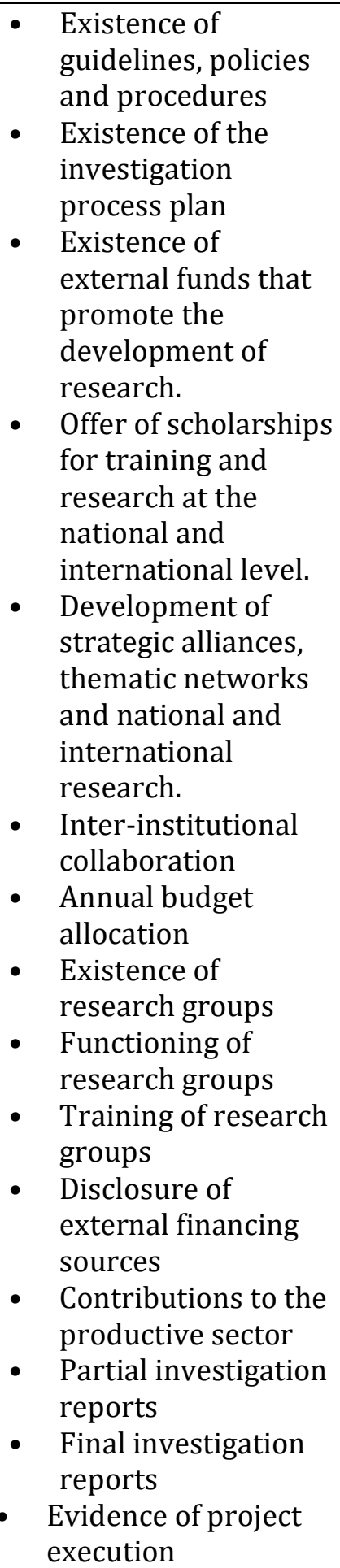 \\
\hline
\end{tabular}




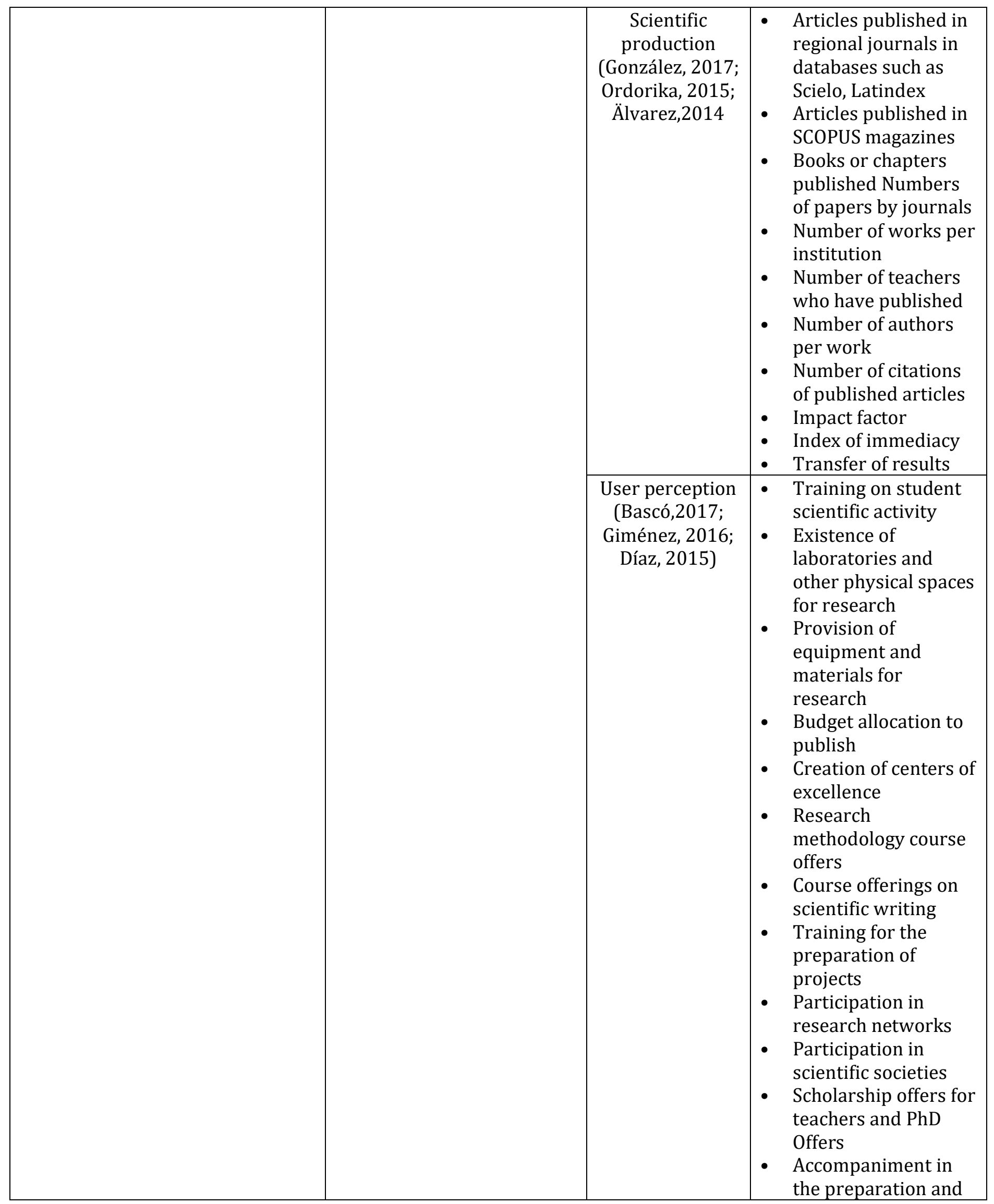




\begin{tabular}{|l|l|l|}
\hline & & $\begin{array}{l}\text { execution of research } \\
\text { projects } \\
\text { Approval time for } \\
\text { research projects } \\
\text { Budget allocation to } \\
\text { execute the projects } \\
\text { Methodological } \\
\text { advice for the } \\
\text { development of } \\
\text { projects } \\
\text { Delay time for } \\
\text { internal procedures }\end{array}$ \\
\end{tabular}

Daher 2019

\section{SOURCES OF FUNDING}

This research received no specific grant from any funding agency in the public, commercial, or not-for-profit sectors.

\section{CONFLICT OF INTEREST}

The author have declared that no competing interests exist.

\section{ACKNOWLEDGMENT}

None.

\section{REFERENCES}

[1] Bascó, Barbón, Solís, Poalasín and Pailiacho. (2017). Diagnosis of student scienti fi c activity in Medicine at the National University of Chimborazo. Educ Med. 18 (3): 154 --- 159

[2] Baron, Robert and Byrne and Donn. (2005). Social psychology. Mexico: Pearson. Prentice Hall. Spain. Madrid

[3] Bordons, Zulueta (1999). Evaluation of scientific activity through bibliometric indicatorsRevEspCardiol. ; 52: 790-800 - Vol. 52 No. 10.

[4] Ceballos, Cantarero, Pascual, (2004). The Bologna treaty and higher education: A comparative experience of introduction of ICTs in economics. Barcelona: Edutec.

[5] National Council for the Evaluation and Accreditation of Higher Education. (2009). Institutional performance evaluation of the universities and polytechnic schools of Ecuador. Quito: CONEA.

[6] De las Salas, (2014). Attitude of the university student towards research in the Luz nucleus - Eastern Coast of the Lake Legal Deposit: PPI200802ZU2980 / ISSN: 1856-9331. Edition No 18 - Year 9 - October 2014 - March 2015.

[7] Diez de Castro, (2001). Administration and Direction. Editorial Mc Graw Hill. Interamericana de España Garrido, (2001) Bibliometric analysis of scientific productivity in the MAPFRE MEDICINA journal. FREMAP Madrid II Assistance Center of the Sánchez F. 2 Gala .. Mapfre Medicina, 2001; 12: 157-167 Jiménez, Terriquez, Robles, (2011).

[8] Evaluation of the academic satisfaction of the students of the Autonomous University of Nayarit. Revista Fuente, 2 (6), 46-56 López, (2014). Quality management models. European Model of Excellence. Spain: Colegio Sagrado Corazón Jesuitas León. Available at: http://www.jesuitasleon.es/calidad/Modelos\%20de\%20gestion\% 20de\% 20calidad.pdfMantilla, (2007)

[9] Research management: differentiations and relationships. Available at: http://revistas.usta.edu.co/index.php/hallazgos/article/viewFile/1668/1817Molero, Contreras, Casanova, (2016). 
[10] Knowledge management as a tool for research productivity in the university sector. Legal Deposit: PPI200802ZU2980 / ISSN: 1856-9331. Edition No 21 Muñoz, (2000).

[11] Towards an intercultural education: Approaches and Models. Complutense University of Madrid: Education meetings. $1, \quad 81-106 . D \quad$ Dipsonible http://qspace.library.queensu.ca/bitstream/1974/628/1/sedano.pdfPezántez, (2011).

[12] Management and quality indicators of Higher Education. Master in Integrated Quality, Environment and Safety Management Systems. SaleRodríguez Polytechnic University, Castañeda, (2001).

[13] Teachers in research and innovation contexts. In Revista Iberoamericana de Educación, 25, 103-146. Recovered from the site: http://www.rieoei.org/rie25a05.htm Sánchez, (2005).

[14] Teach to investigate. A new didactics in the training of researchers in social and human sciences. Mexico. Plaza and Valdés Editores Sancho, (1990). Bibliometric indicators used in the evaluation of science and technology. Bibliographic review. Rev. Esp. Doc. Cient., K3, 3-4, 19900ñate, Urdaneta, (2016).

[15] Knowledge management for the training of researchers in university environments. Legal Deposit: PPI200802ZU2980 / ISSN: 1856-9331. Edition No 21 Ucrós, Sanchez and Cardeño, (2015).

[16] job satisfaction in teaching, research and extension, of higher education professors in Guajira Colombia. International Journal Administration \& Finance Vol. 8, No. 4, 2015, pp. 107-116. Available at: ftp://ftp.repec.org/opt/ReDIF/RePEc/ibf/riafin/riaf-v8n4-2015/RIAF-V8N4-2015-7.pdfVanderZanden, James, (1990).

[17] Manual of social psychology. Madrid: Paidos IbéricaAlonso, Tannuri, Cabrini, Pandiella, and Benavent. (2016).

[18] A bibliometric analysis in the area of Medicine: scientific collaboration between Brazil and Spain (2002-2011). Library Research: Archivonomy, Library Science and Information. Volume 30, Issue 69, May - August 2016, Pages205-230. Available at: https://www.sciencedirect.com/science/article/pii/S0187358X163002 Alvarado, Morales, Aguayo, (2016).

[19] Perception of educational quality: case applied to students of the Autonomous University of Nuevo León and the Instituto Tecnológico de Estudios Superiores de Monterrey.Revistadelaeducación superior printed version ISSN 0185-2760. Rev. educ. sup vol.45 no.180, Available at: http://www.scielo.org.mx/scielo.php?pid=S0185-27602016000400055\&script=sci_arttex, (2000).

[20] The Leadership of Educational Processes. In: A. Villa. (Coord). Leadership and Learning Organizations. III International Congress on Center Management. (1st ed., Chap. ISBN: 84-271-2338-00, pp. 299-330). Bilbao. Spain: Editorial Messenger Álvarez, Juncosa, (2014). 